\title{
Sustainable Development and Public Administration: Challenges and Innovation in Citizen Engagement
}

William McDonald*

Department of Emergency Management, State University of New York, Empire State College, Staten Island, New York, USA

\begin{abstract}
This article explores the challenges and practices of citizenship engagement in sustainability policymaking in the local governments worldwide. The analysis focuses on 52 case studies from the ICLEI-local governments [1] for sustainability database. Cases document successful sustainability experiences from 48 urban communities in 20 different countries. The article offers a broader-than-national overview of existing public administration practices to advance our understanding of how they evolve in response to the global environmental challenges. The analysis concludes that successful sustainability policies may take place disregarding the size or geographical location of the urban community, which is consistent with previous literature on the topic. Moreover, the study explores in detail cases with the strongest citizen engagement and suggests that bottom-up public participation is particularly strong when citizens have to deal with a specific problem. The strongest government-led frameworks of support for citizen engagement have been found in the medium-size European cities.
\end{abstract}

Keywords: Sustainable development; Public administration; Citizen engagement; Government

\section{Introduction}

The global environmental challenges have been affecting all areas of human development in the recent decades. The growing public concern about the environment calls for a response from public administration bodies around the world, at the international, regional, and local levels. Cities, states, and countries adopt new sustainability and climate change policies in an attempt to improve their environmental impact and the quality of life for its citizens. The process of deliberation, adoption, and implementation of such policies is not straightforward as sustainability issues tend to be complex and overlapping with other areas of public concern, including health and safety, transportation, education, etc.

In the field of public administration, scholars have been conceptualizing new and emerging practices of integrating and acting upon environmental concerns through local and regional governments' sustainability policies. For example, a recent special issue of PAR provides some important insights into environmental policy, governance and regulations. There is clear evidence that local governments keep taking up and acting upon sustainability challenges in various ways. There also seems to be an agreement in the literature that stakeholder engagement and participatory processes play an important positive role in developing and implementing sustainability policies at the local level. In places where environmental problems are particularly acute and difficult (e.g., bad air quality, water pollution, etc.), public engagement may be especially strong.

Despite active development in the recent decades, sustainability policies and practices are a relatively new focus for public administration bodies. There is a lot of innovation happening as to how to best arrange these efforts within existing administrative and bureaucratic structures. Does this mean that public administration is evolving to embrace and better address environmental concerns? More specifically, do sustainability challenges encourage and bring about more participatory action than other areas of public concern? These broad questions help frame this inquiry. While much research in the field of public administration concerns specifically cities and local governments in the USA, a country with a long-standing democratic participatory tradition, public administrations in other countries around the world face similar challenges. There is little research available examining how sustainability and environmental concerns affect public administration practices worldwide.

This article addresses this gap and focuses on the role of stakeholder engagement in the sustainability efforts of the local governments. According to the UNEP [2], 'stakeholders' in sustainable development include farmers, women, scientific and technological community, children and youth, indigenous peoples and their communities, workers and trade unions, and business and industry. This analysis looks closely at which stakeholders are usually engaged in the process of designing sustainability policies at the local level and what is the participation of the local communities as the recipients of the outcomes of sustainability policies. It explores successful case studies from 48 local communities in 20 different countries to see what role stakeholder engagement and community participation play in the implementation of sustainability projects. The analysis covers 52 case studies from the library of ICLEI-local governments for sustainability, a useful resource for good practice examples of sustainability projects from around the world. The sample includes the most recent cases for the past 5 years.

\section{Environmental Challenges and Public Administration}

Recent public administration literature has been focusing increasingly on the impact of the environmental challenges and of the concept of sustainable development on the local governments. Considering the growing prominence of these concerns among the public, it is only natural that public administrations at different levels react with new policies and initiatives. Since the issues are relatively

*Corresponding author: William McDonald, Department of Emergency Management, State University of New York, Empire State College, Staten Island, New York, USA, Tel: +9179396232; E-mail: William.mcdonald@esc.edu

Received August 01, 2017; Accepted August 03, 2017; Published August 08, 2017

Citation: McDonald W (2017) Sustainable Development and Public Administration Challenges and Innovation in Citizen Engagement. Review Pub Administration Manag 5: 219. doi:10.4172/2315-7844.1000219

Copyright: (๑) 2017 McDonald W. This is an open-access article distributed under the terms of the Creative Commons Attribution License, which permits unrestricted use, distribution, and reproduction in any medium, provided the original author and source are credited. 
new and wide-ranging, the ways that local governments address them varies greatly. The need to deal with specific environmental challenges, types of decision-making processes, and availability of resources have all been mentioned in the literature as the factors influencing local governments' sustainability policies [3-6].

Much of the response depends on the ability of the city administration to formulate and execute plans reflecting the principles of sustainable development [7]. Wang et al. [8] explored sustainability practices in the cities in the United States (USA) and suggest that a useful framework for planning efforts is capacity building, which involves developing technical and financial support of the policies and increasing managerial execution. The authors argue that the role of public managers is to take the lead in developing sustainability goals and translating them in management and operations. Some researchers have argued that Sustainable Development Goals (SDGs) and specifically SDG 11 on sustainable communities may serve as a helpful general guidance for formulating local sustainability goals [9]. Planning is also important in designing public participation processes [10], which has direct implications for sustainability policies at a local level.

Collaborative aspect and public participation in sustainability efforts also received much attention in the literature [11-18]. While Koontz and Thomas [19] have argued that there is still no strong evidence to link collaborative environmental management to improved environmental outcomes, they accept the fact that collaboration plays a prominent role in addressing environmental challenges at a national level (in the USA). Portney and Berry [20] have found that the cities most committed to sustainability tend to be more participatory places.

Considering transboundary and global nature of sustainability challenges, the emergence of networks of local governments and cities reflects the efforts of these actors to benefit from the synergies of collaboration. These networks focus on sharing knowledge and best practices, on leading by example and on advocacy and representation in the international climate and sustainability governance. Growing scope and efficiency of international cooperation on climate change among cities and local governments led Betsill and Bulkeley [21] to propose a theory of multilevel governance of climate change.

One of the oldest and most prominent transnational networks for local governments is ICLEI-local governments for sustainability. ICLEI was formed in 1990 as an international council for local environmental initiatives. However, in 2003 the name changed to ICLEI-local governments for sustainability to reflect better the nature of challenges facing local governments. The new mandate and scope of action concerned not only environmental issues but also more broadly sustainability efforts. The headquarters of the organization are in Toronto, Canada, and there are two international secretariats in Bonn, Germany, and Washington D.C., USA. Currently, the membership of ICLEI represents over 1,500 local and regions governments in more than 100 states. The organization offers tools and develops common methodologies to address similar sustainability challenges. It also serves as a lead advocacy group to ensure fair representation of local governments at the international climate and sustainability talks. ICLEI has a vast library of case studies aimed to offer good practice examples to any interested party. In addition to the undeniable practical benefits to local policy makers, such libraries also offer a wealth of information for researchers.

\section{Methods}

To gain insights into the international sustainability practices of the local governments and the role of public participation in those processes, this analysis taps into the library of 'best practice' case studies from around the world developed by ICLEI. Currently, the database contains 193 cases dating back to 2009. For this evidencebased analysis, I have selected 52 most recent case studies published in the past five years (since 2012). The case studies cover 20 countries on all continents. Each case study presents an example of a successful sustainability project or initiative undertaken at a local level. The scope of projects ranges widely from small community center improvements in South Africa to regenerating vast industrial areas in Germany, or even mega-cities examples, like smart parking project initiative in San Francisco.

Each case study is between six and eight pages long and offers a standardized description of the project scope and its implementation process. Some cases have detailed sections on stakeholder engagement, while others barely mention it. It is important to acknowledge that the insights may be limited due to the case study format: some practices may have been omitted, while others lack detailed descriptions. For the purpose of this study, however, the level of detail in the case reports is sufficient as it provides a good idea of what the general trends and modalities of participation are.

Each case study was reviewed and assigned an assessment rating of the citizen engagement in the process. Cases with active civil society engagement, especially representing the interests of the local community, received 'high' participation rating. Cases with limited references to stakeholder and local community engagement received 'medium' rating. Finally, cases, which had no or poor references to stakeholder engagement, received the 'low' rating. The rating reflects the analysis based solely on data available in case studies. In addition to the ratings, notes for the cases recorded modalities of civil society and stakeholder engagement, specific participation activities, and innovative initiatives of the local administrations.

\section{Results}

Out of 52 case studies, 23 demonstrated low levels of stakeholder engagement, 16-medium levels, and 13 cases showed high levels of stakeholder engagement, especially of the local community.

Many cases with low levels of public participation contained declarative statements mentioning the importance of stakeholder engagement. For example, case study 146 on green cleaning (Reykjavik, Iceland) states that involving stakeholders in the preparation phase is important' (p. 5)-and does not go on to explain or elaborate this view. Another case study 165 on developing non-motorized transport (Bogota, Colombia) notes that citizens must be included in the process and that advocacy is complementary to the infrastructure and municipal efforts (p. 4). Statements like these, while seemingly acknowledging the presence and the importance of participatory processes in decision-making, at the same time are too abstract and do not provide sufficient level of detail to assess actual practices of public participation in sustainability policy making.

Low levels of public participation, according to the case studies, occurred in various geographical contexts and in countries with different levels of wealth: Brazil, Peru, Mexico, Colombia, USA, Portugal, Spain, Italy, Germany, Finland, Iceland, Japan, India, Indonesia, Chinese Taipei, China, and South Africa. It is worth acknowledging that little or no discussion of public participation in some cases may have been due to limited space and the format of the case study. Considering their nature, for example, some projects, like case 158 on 'Cycling public transport' (Munster, Germany), may have 
had more public engagement than reflected in the reports. However, the analysis in the next section relies solely on data available in case studies and does not make speculations or engage with sources of data for each project other than the ICLEI case studies database.

Sixteen case studies demonstrated medium-level public engagement in the local sustainability initiatives. The stories come from Brazil, Mexico, Spain, South Korea, South Africa, India, Germany, Italy, USA, and Australia. Examples of public participation activities include public consultations with the residents in cases 167 'one neighborhood. One month. No cars' (Suwon, South Korea); civil society action pushing for low-carbon public transport in case 192 'integrating greenhouse gas inventories as a decision-making tool' (Fortaleza, Brazil); educational, outreach and showcasing efforts in cases 188 on achieving low-carbon local development (KwaDukuza and Steve Tshwete Local Municipalities, South Africa) and 164 on integrated transportation system (Boulder, Colorado, USA). In several cases, citizens formed dedicated groups and networks to participate in sustainability-related decision-making processes, including cases 170 on creating a new climate culture (Essen, Germany) and 151 on building an eco-city (Melbourne, Australia). In a number of cases, local municipalities provided an opportunity for the local community to give feedback on the operation or implementation of the new project or policy, for example, in cases 156 on cycling 2020 concept (Freiburg, Germany) and in 184 on integrating bikes in the public transportation system (Sorocaba, Brazil).

Finally, thirteen case studies have received a high public participation rating and they took place in Germany, Sweden, France, Brazil, Colombia, South Africa, Chinese Taipei, South Korea, Canada and the USA. Five cases focused specifically on the engagement with the local community, including cases 147 on 'Community-based local action' (Betim, Brazil); 153 on 'Environmental education and participation for sustainable development' (Helsingborg, Sweden); 191 on 'Enhancing the participatory process when building a municipal climate change agenda' (Recife, Brazil); 187 on community solar solutions (Steve Tshwete, South Africa); and 171 on 'Participatory energy transition-effective public relations for comprehensive climate action' (Dortmund, Germany). Other projects concerned specific sustainability challenges, in addressing which the public took an active part, such as cases 193 on water management in urban re-development (Dortmund, Germany); 182 on building safer after the Kaohsiung gas explosions (Chinese Taipei); 179 on solid waste management (Medellin, Colombia); 163 on building light rail transit (Portland, Oregon, USA); 157 on pollution charges (Milan, Italy); and 154 'One Less Nuclear Plant' initiative (Seoul, South Korea). Table 1 provides a summary of the key public engagement activities for thirteen cases.

It is important to note that the vast majority of case studies (47) explicitly acknowledge the importance of planning in achieving successful results from sustainability policies. Most local efforts have at the core specific plans and goals to help guide their efforts. Moreover, according to the case studies, sustainability policies have initiated changes in the local administrations' structures and practices in almost all cases. Such changes range from creating a new post of environmental officer (case 188 in South Africa) to creating new committees and departments to deal with specific and broad sustainability challenges.

\section{Discussion}

The first finding of the analysis is that there is no visible pattern to the distribution of public participation in local sustainability initiatives, which goes in line with the conclusions of some previous studies
$[2,4,7,22-24]$. In each category (low, medium, and high levels of public participation), there were examples from large and small cities, projects with various scopes and budgets, first-time transformations and continuous improvements of existing sustainability initiatives. One unifying feature of all cases is the leadership and commitment of the local administration, which facilitated successful formulation, design, and implementation of the sustainability policies. This is unsurprising considering that case studies were submitted to ICLEI, an organization working to advance sustainability through strong and committed local governments.

The second important finding concerns the role of democratic participatory process and engagement of the local community in the policy making. The analysis suggests that public participation is neither a pre-requisite, nor a by-product of successful sustainability policies. Almost half of all cases hardly mention public engagement or civil society activities. Cases with low levels of public participation primarily revolve around technically complex processes, such as recovering energy from biogas produced in wastewater treatment plants (case 189, Almada, Portugal); introducing clean renewable diesel fuel for buses (case 152, Helsinki, Finland), developing and implementing sustainable certification standards (case 185, Belo Horizonte, Brazil), using technology for smart parking management (case 162, San Francisco, USA), or optimization of public transportation (cases 166 on improving accessibility in a historic hilly town in Perugia, Italy; and 168 on eco-mobile city with integrated public transport in Kaohsiung, Chinese Taipei), etc.

Most cases with low participation required engagement of technical experts and of the private sector actors, working in the relevant field, which warranted public procurement and tender procedures. Cases with low-level public participation include situations when the local government is improving an already existing sustainability initiative, which had already been supported by the citizens (e.g., 159 on car sharing in Bremen, Germany), as well as large-scale infrastructural projects (e.g., cases 142 on solar cities program in Thane, India and 140 on eco-city building plan in Rizhao, China).

In some cases, with low rating, however, public participation could have been strengthened. For example, a city effort to transform towards low-emission development in Balikpapan, Indonesia (case 183) contains only references to collaborations and consultations among various levels of the government (local branches, national ministries), a few largest utilities companies, and external stakeholders, such as the Danish embassy. Considering that the idea behind the case study is of high importance and relevance to the local community, it is surprising that the administration of Balikpapan did not make efforts to engage the public into planning its sustainability initiatives.

Nine out of eighteen cases with medium-level public engagement come from 'the Global North' (Australia, Canada, USA, Germany, Italy, and Spain), the rest are split among South Africa, Brazil, South Korea, Mexico, and India. Among the cases with medium-level public engagement, public participation practices are diverse and roughly fall into two categories: (1) public debates and consultations (including feedback to already implemented policies) and (2) formation of civil society representative bodies (groups, networks, committees, etc.). While the purpose of both types of activities was the same (to provide feedback and to ensure sustainability policies reflect the local community's views), there is an important conceptual distinction between the two. Thus, public consultations, debates, and feedback platforms were initiated by the local governments, while the second type of practices represented primarily bottom-up initiatives. 


\begin{tabular}{|c|c|c|c|}
\hline No. & Location & Case study name & Public participation activities \\
\hline 1 & Dortmund, Germany & $\begin{array}{l}\text { 193-A greener tomorrow: } \\
\text { Water management in urban } \\
\text { redevelopment }\end{array}$ & $\begin{array}{l}\text { Included residents of the redeveloped area into the process of planning and designing the project } \\
\text { through workshops. } \\
\text { Initial skepticism from the local community could be overcome through stakeholder engagement } \\
\text { and because the project provided clear benefits to the local community. (recreational facilities, } \\
\text { greater green coverage). The project ensured diversity of funding and leadership, 'where no single } \\
\text { government member, developer, or investor holds a majority of the power in the project allowed for } \\
\text { various funding and brainstorming to develop' (p. 5). The Mayor was influential and served as a } \\
\text { unifying figure for the public. }\end{array}$ \\
\hline 2 & Recife, Brazil & $\begin{array}{l}\text { 191-Enhancing the participatory } \\
\text { process when building a municipal } \\
\text { climate change agenda, Urban- } \\
\text { LEDS }\end{array}$ & $\begin{array}{l}\text { The city organized a series of consultations and workshops, which included civil society groups. } \\
\text { This participation allowed all interested stakeholders, including the local community, to give } \\
\text { feedback on policy development and contribute to the 'popular agenda'. Civil servants and civil } \\
\text { society representatives played a crucial role in spreading the information to the community could } \\
\text { create a cross-cutting legal framework. }\end{array}$ \\
\hline 3 & $\begin{array}{l}\text { Steve Tshwete, South } \\
\text { Africa }\end{array}$ & $\begin{array}{l}\text { 187-Doornkop Community Solar } \\
\text { Solutions, Urban-LEDS }\end{array}$ & $\begin{array}{l}\text { It was the decision of the local community to try to go off the grid, articulated and supported by the } \\
\text { local youth co-op. The local municipality organized community showcase initiative for solar power; } \\
\text { awareness and education efforts were a priority. Strong engagement of external stakeholders } \\
\text { (ICLEI, consultants) contributed to capacity building. }\end{array}$ \\
\hline 4 & $\begin{array}{l}\text { Kaohsiung, Chinese } \\
\text { Taipei }\end{array}$ & $\begin{array}{l}\text { 182-Building back safer: One } \\
\text { year after the Kaohsiung gas } \\
\text { explosions }\end{array}$ & $\begin{array}{l}\text { Initially, the local community rallied to support the victims of the tragedy (community care groups). } \\
\text { The city government provided a framework and encouraged the local community to get involved } \\
\text { in actions and initiatives to support the victims (religious praying events, memorial artistic } \\
\text { performances, exhibitions, and concerts). Inter-governmental cooperation and stronger collaboration } \\
\text { with community (lessons from Canada, Japan, and the USA.) }\end{array}$ \\
\hline 5 & Medellin, Colombia & $\begin{array}{l}\text { 179-A new approach to solid } \\
\text { waste management in Medellín: } \\
\text { matching problems with solutions }\end{array}$ & $\begin{array}{l}\text { The city organized strong education outreach initiatives in the community to raise awareness and } \\
\text { improve waste separation practices and general social recognition of waste collectors. Fragmented } \\
\text { initiative lacking strong legal support meet resistance from the public. }\end{array}$ \\
\hline 6 & $\begin{array}{l}\text { Portland, Oregon, } \\
\text { USA }\end{array}$ & $\begin{array}{l}\text { 163-Portland-Milwaukie Light } \\
\text { Rail Transit Project: Managing } \\
\text { growth sustainably through transit } \\
\text { alternatives }\end{array}$ & $\begin{array}{l}\text { Active community participation in some neighborhoods led to the selection of the project as a locally } \\
\text { preferred Alternative and to its implementation. Local residents and other interested stakeholder } \\
\text { formed a citizens advisory committee. }\end{array}$ \\
\hline 7 & Seoul, South Korea & $\begin{array}{l}\text { 154-The "One Less Nuclear Power } \\
\text { Plant" Initiative }\end{array}$ & $\begin{array}{l}\text { The metropolitan government organized a citizen commission of } 17 \text { reputable figures from civic } \\
\text { groups, the business and media arena as well as religious, educational and cultural sectors, in } \\
\text { order to garner its citizens' power (p.2). Civil society initiatives contribute to the large-scale action. } \\
\text { The encourages the citizens to take the lead and organized the 'Energy Guardian Angels' program } \\
\text { (young leaders in energy saving and volunteer activities). }\end{array}$ \\
\hline 8 & Helsingborg, Sweden & $\begin{array}{l}\text { 153-Environmental education and } \\
\text { participation for local sustainable } \\
\text { development }\end{array}$ & $\begin{array}{l}\text { Municipality-initiated environmental education for primary and high school students to increase the } \\
\text { engagement into the local sustainability programs. The city has a very strong tradition of democratic } \\
\text { participation in sustainability policymaking. Annual environment workshop and sustainable school } \\
\text { campus initiatives developed by the municipality staff but taught by the school teachers. }\end{array}$ \\
\hline 9 & Betim, Brazil & 147-Community based local action & $\begin{array}{l}\text { The local community decided to organize itself to seek access to reliable energy and water } \\
\text { services. It stimulated coordinated action by collaborating with an energy provider and the municipal } \\
\text { government and secured support from the renewable energies and energy efficiency reference } \\
\text { center to achieve tangible improvements in quality of life and social inclusion. The local community } \\
\text { action led to the local government giving greater priority to the demands of the neighborhood. }\end{array}$ \\
\hline 10 & Dortmund, Germany & $\begin{array}{l}\text { 171-Participatory energy } \\
\text { transition-effective public relations } \\
\text { for comprehensive climate action }\end{array}$ & $\begin{array}{l}\text { Through a strategic and engaging PR campaign, the local government encouraged coordinated } \\
\text { action within a socially and culturally diverse stakeholders. Dialogue and engagement of members } \\
\text { from all demographics is achieved through different thematic fora. Shared climate campaign } \\
\text { brand with the local soccer team to increase the feelings of association and support from the local } \\
\text { community. An independent citizen service center, funded by the city, provides consultation on } \\
\text { topics relating to energy efficient construction and the renovation of buildings, renewable energy, } \\
\text { power consumption and mobility. }\end{array}$ \\
\hline 11 & Nantes, France & 145-A European Green Capital & $\begin{array}{l}\text { The city actively encouraged public action and stakeholder engagement through a number of } \\
\text { initiatives: 'Development Council' (proposed by the mayor Jean-Marc Ayrault to increase citizen } \\
\text { involvement) which is composed of representatives from civil society, providing advice to Nantes } \\
\text { through reports and proposals. A strong network of local environmental NGOs, financially supported } \\
\text { by Nantes Métropole. 'Climate Workshop', where } 150 \text { households worked with Nantes Métropole in } \\
\text { order to review and co-construct the future climate policy. 'Nantes } 2030 \text { my city tomorrow', a two- } \\
\text { year participatory process for the citizens of the } 24 \text { cities composing the Nantes agglomeration. Its } \\
\text { goal is to establish a cohesive planning framework for the entire urban agglomeration with all the } \\
\text { relevant actors, citizens, businesses, NGOs, academics, students, etc. }\end{array}$ \\
\hline 12 & Bottrop, Germany & $\begin{array}{l}\text { 169-Innovation City Ruhr-Model } \\
\text { City Bottrop: revitalizing an } \\
\text { industrial region through low- } \\
\text { carbon redevelopment and active } \\
\text { public-private partnerships }\end{array}$ & $\begin{array}{l}\text { The city believes that active public and private participation is of high importance. Strong support } \\
\text { from the local community towards sustainable action. The city offers individualized energy } \\
\text { consultations to citizens, which motivates higher energy efficiency. Bottom-up district management } \\
\text { committees were established for the redevelopment of the seven pilot districts through citizen } \\
\text { planning workshops. They also consult building owners, tenants and businesses and involved } \\
\text { in outreach to schools. Innovation City Management has organized networks of local craftsmen, } \\
\text { architects and energy consultants and established a partner network for technology and process } \\
\text { related innovation. Grassroots energy transition: 'prosumers' (as opposed to consumers) not only } \\
\text { use energy efficiently because of the widespread awareness, but also take part in its generation. }\end{array}$ \\
\hline 13 & Toronto, Canada & $\begin{array}{l}\text { 149-Moving from assessment to } \\
\text { action on climate change }\end{array}$ & $\begin{array}{l}\text { Creation of Weather Wise Partnership, a non-profit group which brought on board various } \\
\text { stakeholders ranging from key corporate actors in the city, to municipal staff, NGO's and community } \\
\text { groups in an effort to (1) identify actions to reduce climate change risks and (2) raise awareness of } \\
\text { the risks associated with climate change. }\end{array}$ \\
\hline
\end{tabular}

Table 1: Provides a summary of the key public engagement activities for each of the thirteen cases. 
In all cases, there was a strong lead from the local government, which encouraged stakeholder engagement. However, as the case 192 on integrating GHG inventories into decision-making in Fortaleza, Brazil, demonstrates, sometimes municipal sustainability policies that emerged as a response to civil society concerns and action later led to forming stakeholder groups, which did not include the local community (rather, larger private actors). It is unclear from the case studies whether bottom-up formation of citizen's action groups and initiatives had any impact on the structural changes in the local administrations. Although certain changes in the structure of public administrations occurred in most cases (creation of new departments, committees, etc.), there is not enough data to conclude that public participation caused these changes. More in-depth case studies could help trace the connection or lack thereof.

Out of thirteen case studies with high levels of public engagement, seven come from 'the Global North' (Germany, Sweden, France, USA, and Canada) and six come from Brazil, South Africa, Chinese Taipei, Colombia, and South Korea. The European context offers cases from countries and cities with a strong tradition of democratic participation in local decision-making. Three out of seven cases take place in Germany, two in Dortmund and one in Bottrop, both medium-size cities. In an attempt to revitalize and re-develop formerly highlyindustrialized urban areas, municipal administrations of Dortmund and Bottrop launched large-scale transformative agendas. Their sustainability and climate change policies are closely intertwined and put the strongest emphasis on public participation and stakeholder engagement. Consultations with citizens, especially the residents of the areas allocated for re-development, take place in both cities on a regular basis, allowing the local community voice their concerns and views on the project.

These communications do not only take shape of workshops. The city of Dortmund (case 171), for example, established different thematic fora to 'speak' to its inhabitants from different demographics (although the case study report does not specify which ones). Many initiatives supported by the local governments in Germany are bottom-up, including the formation of bottom-up district management committees in Bottrop to oversee various re-development plans. In Germany, as case studies indicate, the public has a strong commitment to sustainability and the citizens are keen on taking active part in decision-making, which affects their quality of life and their environment.

Similarly, active public engagement takes place in Nantes, France. However, most citizen engagement programs highlighted in the case study are initiated by the local government. While it is logical to assume that these policies emerged as a response to strong public concern, existing data does not allow to make conclusions about the role of the public shaping the actions of the local government. In Nantes, the local government went to a great length to engage citizens in the planning and formulation of the city's climate change policies. They organized a development council to channel advice and feedback to the government from the civil society and a climate workshop to include local households in the planning process. The municipality also supports a strong network of local environmental NGOs and established another participatory process known as Nantes 2030 my city tomorrow to encourage further engagement and deliberation.

Strong leadership from the local government and the support towards public engagement is also evident in other cases. For example, in Toronto, Canada, the city facilitated the creation of WeatehrWise Partnership, a non-profit group, which includes stakeholders from primarily private sector but also representatives of different civil society groups. The group provides advice to the city on climate risks and potential solutions and disseminates information to the local community.

One key theme that is common for all case studies with high levels of public engagement is awareness raising and education efforts of the local administrations. Free consultations to the public and PR campaigns to change public attitudes and behavior have been present in many cases. The strongest case of educational efforts is the one from Helsingborg, Sweden. It explains a long-term project of the local municipality to mainstream environmental and sustainability concerns by organizing annual workshops and a 'sustainable school campus' program for schoolchildren. The idea behind these initiatives is that knowledge and awareness about environmental challenges, as well as hands-on participatory experience in addressing these issues will prepare the new generation of environmentally conscious and active citizens.

In other geographical contexts, local municipality's awareness raising efforts were particularly strong in Medellin, Colombia, where the government undertook a major effort to change public attitudes towards waste management in general and to improve social recognition of waste collectors in particular. In Recife, Brazil, the local government took active steps to engage the community into the planning of its climate change policies and the key advocates responsible for disseminating information in the process were civil servants and civil society representatives. Similarly, to Sweden, in Seoul, South Korea, the metropolitan government leads a number of educational and awareness raising initiatives to encourage low energy lifestyles. One of the initiatives, the 'Energy Guardian Angels', targets specifically the younger generation.

Another prominent theme in all case studies with high levels of public engagement is self-organizing citizens. Interestingly, the most obvious cases of grassroots efforts were also the smallest in scale. In Steve Tschwete, South Africa, for example, the local community decided to go off grid and initiated the process, which the local government took to the completion, with the help of external stakeholders. In Betim, Brazil, another local community organized itself to arrange for the provision of basic services, such as water and electricity, and engaged the local government, international and national organizations, and the key private players. In Portland, Oregon, USA, residents of a particular neighborhood also managed to organize themselves and lobby a more sustainable transportation alternative. In Kaohsiung, Chinese Taipei, citizen engagement had a more humanitarian shape as the local community strengthened itself in a response to a major disaster that affected the city.

\section{Conclusion}

A critical analysis of fifty-two case studies of successful sustainability projects undertaken by the local governments around the world yielded several conclusions. First, successful projects can take place in any geographical context and in any size urban community. World capitals among the case studies had both examples of high levels of public engagement (Seoul, South Korea), medium levels (Milan, Italy), and low levels (Helsinki, Finalnd). Similarly, smaller-scale projects in medium-size and small urban communities varied in their public engagement practices. Success of sustainability projects, therefore, depends on individual characteristics of the city/municipality, which strongly supports past findings in the literature (Feiock and Bae 2011; Feiock, Tavares, and Lubell 2008; Krause 2010; Lubell, Feiock, and 
Ramirez de la Cruz 2009; O’Connell 2009; Wang, Hawkins, Lebredo, and Berman 2012).

Second, based on the existing dataset, it is possible to conclude that public participation is neither a pre-requisite, nor an outcome of successful sustainability projects. Many cases with no or little public participation were technical and complex in nature and required the engagement of technical experts (such as the case of biogas use optimization in Almada, Portugal, or introducing biodiesel in the public transport system un Helsinki, Finland). Often, also, city's efforts to improve existing sustainability policies and practices take place through quiet internal processes within the municipality and without active engagement of the public (such as improving cycling infrastructures in Bremen and Muenster, Germany).

This article provides a broader overview of the existing sustainability efforts of the local governments from around the world. This allows to widen the scope of inquiry into the evolution of public administration responses to sustainability challenges and to explore the patterns and key themes related to public participation in sustainability policy making. However, it is important to acknowledge that the level of detail provided in ICLEI case study reports does not permit a truly indepth exploration possible only through in-depth individual case study approach. More detailed individual cases from different geographical contexts could help build a stronger understanding of how the public administrations evolve in light of the global sustainability challenges.

\section{References}

1. ICLEI World Secretariat ICLEI-Local Governments for sustainability. Case Study Library.

2. UNEP (2015) Handbook for stakeholder engagement.

3. Feiock RC, Bae J (2011) Politics, institutions and entrepreneurship: City decisions leading to inventoried GHG emissions. Carbon Manage 2: 443-53.

4. Krause RM, Feiock RC, Hawkins CV (2016) The administrative organization of sustainability within local government. J Public Admin Res Theory 26: 113-127.

5. Feiock RC, Tavares A, Lubell M (2008) Policy instrument choices for growth management and land use regulation. J Policy Stud 36: 461-80.

6. Mar KL, Feiock RC, Handy S (2009) City adoption of environmentally sustainable policies in California's central valley. J Ame Plann Assoc 75: 293308.

7. Conroy MM, Berke P (2004) What makes a good sustainable development plan?
An analysis of factors that influence principles of sustainable development. Env Plann 36: 1381-96.

8. Wang X, Hawkins CV, Lebredo N, Berman EM (2012) Capacity to sustain sustainability: A study of USA. cities. Public Admin Rev 72: 841-853.

9. Barnett C, Susan $P$ (2016) Ideas, implementation and indicators: Epistemologies of the post-2015 urban agenda. Environment and Urbanization 28: 87-98.

10. Bryson JM, Quick KS, Slotterback CS, Crosby BC (2013) Designing public participation processes. Public Admin Rev 73: 23-34.

11. Ansell C, Alison G (2008) Collaborative governance in theory and practice. J Public Adm Res Theory 18: 543-571.

12. Beierle TC, Cayford J (2002) Democracy in practice: public participation in environmental decisions. Washington, DC: Resources for the Future 1: 181-182.

13. Calanni, JC, Siddiki SN, Weible CM, Leach WD (2014) Explaining coordination in collaborative partnerships and clarifying the scope of the belief homophily hypothesis. J Public Admin Res Theory 25: 901-927.

14. Kirk E, Nabatchi T, Balogh S (2012) An integrative framework for collaborative governance. J Public Admin Res Theory 22: 1-29.

15. Elena M, Nelson H, Mazmanian DA (2012) Industry influence in stakeholderdriven state climate change planning efforts. J Policy Stud 40: 234-55.

16. Weible CM, Sabatier PA (2009) Coalitions, science, and belief change: Comparing adversarial and collaborative policy subsystems. J Policy Stud 37: 195-212.

17. Henry AD, Lubell M, McCoy M (2011) Belief systems and social capital as drivers of policy network structure: The case of California regional planning. $J$ Public Admin Res Theory 21: 419-444.

18. Siddikki SN, Carboni JL, Koski C, Sadiq AA (2015) How policy rules shape the structure and performance of collaborative governance arrangements. Public Admin Rev 75: 536-547.

19. Koontz TM, Thomas CW (2006) What do we know and need to know about the environmental outcomes of collaborative management? Public Admin Rev 66: $111-121$

20. Portney KE, Berry JM (2010) Participation and the pursuit of sustainability in USA cities. Urban Affairs Rev 46: 119-39.

21. Betsill MM, Bulkeley $H$ (2006) Cities and the multilevel governance of global climate change. Global Gov 12: 141-59.

22. Krause RM (2010) Policy innovation, intergovernmental relations, and the adoption of climate protection initiatives by USA cities. J Urban Aff 33: 45-60.

23. Mark L, Feiock RC, Cruz EE (2009) Local institutions and the politics of Urban growth. Amer J Polit Sci 53: 649-65.

24. Lenahan OC (2009) The impact of local supporters on smart growth policy adoption. J Ame Plann Assoc 7: 281-91. 